\title{
Learner autonomy assessment of English language teaching students in an international program in Thailand
}

\author{
Rosukhon Swatevacharkul $^{1^{*}}$ and Nida Boonma ${ }^{2}$ \\ ${ }^{1}$ English Language Teaching Program, Graduate School of Human Sciences, Assumption University, Bangkok \\ 10240, Thailand \\ ${ }^{2}$ Business English Department, Theodore Maria School of Arts, Assumption University, Sumutprakarn 10570, \\ Thailand
}

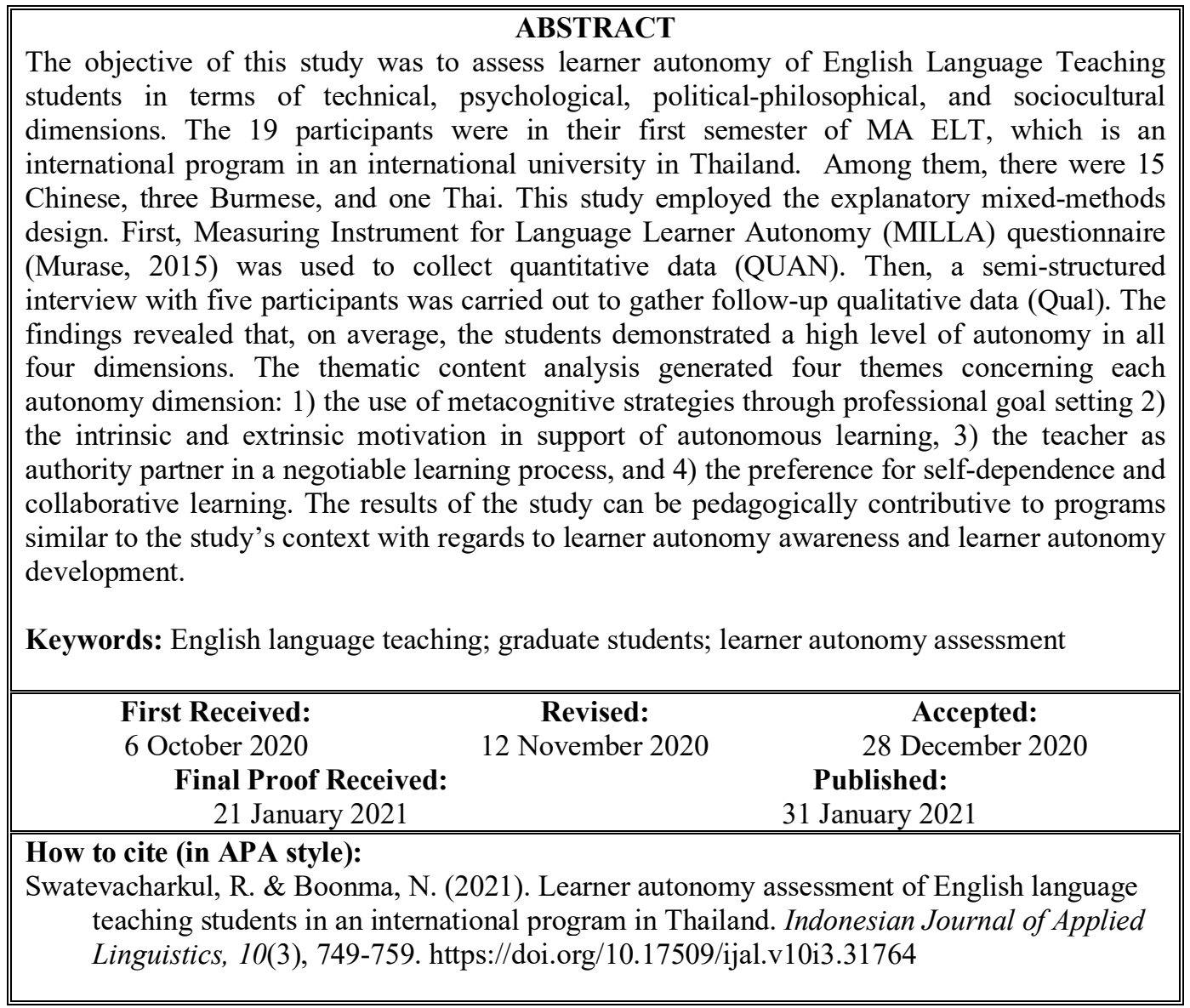

\section{INTRODUCTION}

Regarded as capacity to take charge of one's own learning in a learner-centeredness learning approach, learner autonomy is a prerequisite for effective and successful learning according to its advocates. Autonomous learners are those who are responsible for their own learning and develop critical thinking skills (Benson, 2011). Learner autonomy also contributes to a development of lifelong learning as autonomous learning involving thought, conversation and decisions regarding learning process provides learning to learn benefits (Benson, 2015).

Autonomous learning does not signify learning in isolation and autonomy is socially constructed. Help and support from teachers are, therefore, essential especially during a transition period from teacher-dependence to self-dependence. The important role of teachers in autonomy development process gives rise to a concept of teacher autonomy which is defined by Smith (2000) as "the ability to develop appropriate skills, knowledge, and attitudes for oneself as a teacher in cooperation with others" 
(p. 89). Firmly argued by Little (1995), learner autonomy is dependent on teacher autonomy.

The relationship between teacher and learner autonomy is made clear. Teacher autonomy is crucial for learner-centered classroom atmosphere which is considered a foundation for successful language classroom (Derakhshan \& Taghizadeh, 2020). Learner autonomy development depends on effective teachers who are autonomous and capable of exercising autonomy effectively. Therefore, an attempt to explore learner autonomy of graduate students in an English language teaching (ELT) program who will become teachers of English is worthwhile. As research shows (Derakhshan \& Taghizadeh, 2020), teachers with a higher degree of autonomy are more likely to be successful in their teaching profession than the teachers with a lower level of autonomy. Training graduate students to be autonomous is a prerequisite for their future teaching success and teacher development. It is therefore worthwhile recognizing their degree of learner autonomy as students which may predict their ability to be effective language teachers in a near future.

Several pedagogical benefits can arise from learner autonomy assessment which can be implemented in different learning settings and situations (Tassinari, 2015). It helps the learners to be aware of their own ability which will assist learning improvement and learning process regulation. The assessment is also advantageous for teachers or advisors to realize strengths and weaknesses of each student. Necessary supporting plans can then be instigated to fully foster learner autonomy.

Although several studies yielded positive perceptions of learner autonomy at different educational levels, research carried out with Asian postgraduate students (Arshiyan \& Pishkar, 2015) and with pre-service teachers (Ozturk, 2019) is still limited and thus recommended for further study. Research particularly conducted with postgraduate ELT students who will soon become in-service teachers of English is scarcer. One recent research investigated attitudes toward learner autonomy of students in an ELT program in Thailand also revealed positive perceptions (Swatevacharkul \& Boonma, 2020). To fill the gap, this study attempted to assess the level of learner autonomy in a holistic manner, as suggested by Oxford (2003), of Asian MA students in an international ELT program. The ELT program is content and language integrated learning or CLIL where the English language is a medium of instruction.

It is hoped that this study will be pedagogically contributive to any MA ELT programs similar to the context of this present study to be aware of a degree of learner autonomy of these students who have a potential to promote learner autonomy of their students in the future. Thus, knowing their level of autonomy may possibly predict their readiness to develop autonomy of their future students.

Supported by Palfreyman (2003), teachers do not only have an important role to promote autonomy of their students, but they themselves have to be autonomous learners and practitioners. Additionally, the findings will beneficially guide the programs for curriculum development, material selection and classroom teaching practices. The ELT programs can adjust or employ pedagogies to fully develop autonomy of their students as this can promote deep or deeper learning approaches of the students. As Tassinari (2015) argues, autonomy assessment should aim to be assessment for autonomy. Paralleled to the argument of Brockett and Hiemstar (1993), there must be a balance between pedagogy for autonomy and readiness for autonomy on the part of students.

Therefore, the objective of this paper is to assess learner autonomy of ELT students in terms of technical, psychological, political-philosophical and sociocultural dimensions.

\section{Learner autonomy}

Learner autonomy in language education is referred to many terms, namely learner autonomy, learner independence, self-direction, autonomous learning, and independent learning (Palfreyman, 2003). Holec (1981) defines autonomy as "the ability to manage one's own learning" (p. 7). Although his definition focuses on what autonomous learners should be able to do and does not explain clearly how to do that, it is widely cited and accepted. The ability is not innate, though it can be developed by formal learning in a systematic manner.

Dickinson (1987) defines autonomy as "the situation in which the learner is totally responsible for all of the decisions concerned with his learning and the implementation of those decisions" (p. 11). Subsequently, Benson (1997) provides three definitions of language learning autonomy as follows: autonomy as the act of learning on one's own and the technical ability to do so; autonomy as the internal psychological capacity to self-direct one's own learning; and autonomy as control over the content and processes of one's own learning. Benson's definitions reveal an attempt to derive three components of learner autonomy, that is, a technical, psychological, and political dimension with Oxford's (2003) extension of sociocultural dimension. Dickinson (1995) supports that learners must believe that they have control over their learning success or failure to take responsibility for their own learning.

Synthesizing various definitions of autonomy, Everhard (2015) offers a working definition of autonomy in language learning as "Autonomy is a way of being or sense of self achieved through cooperatively making decisions about learning, through access to both internal and external 
resources. The ability to exercise autonomy depends on particular dispositions and predispositions and fluctuates according to circumstances" (p. 11). In this study, learner autonomy refers to capacity to take responsibility for and self-direct one's own learning. It is composed of technical, psychological, political-philosophical, and sociocultural dimensions.

\section{Assessing learning autonomy}

Backing up by Benson (2011) who confirmed that there is a need for some scale of measurement for autonomy, Murase (2015) reconceptualized Benson's (1997) and Oxford's (2003) learner autonomy and developed a questionnaire to assess learner autonomy consisting of four inter-related dimensions and sub-dimensions which are the conceptual framework of this current study.

First, technical autonomy includes behavioral autonomy which is the ability to use cognitive and metacognitive strategies, such as setting goals, planning and monitoring to take control of own learning. This dimension also incorporates situational autonomy which means the ability to take control of one's learning in the situation where the learners need to perform independent learning.

The second, psychological autonomy, consists of motivational, metacognitive and affective subdimensions. Motivational sub-dimension signifies intrinsic and extrinsic motivation towards learning English, the capacity to take control of own learning by knowing about the strategies to motivate oneself, and the responsibility for success or failure in learning English. Metacognitive sub-dimension means the capacity to take control of own learning by knowing about own learning, which is needs, preferences, strengths and weaknesses. Affective sub-dimension is the capacity to take control of own learning by knowing about one's affective states, namely anxiety, self-esteem, and other emotions and how to control these affective factors.

The third dimension, political-philosophical autonomy, incorporates positive and negative freedom. The former can occur when the learners have freedom to control their learning in terms of content, goals and purposes with the agreement of teachers. The latter occurs in the context of learning English where the learners can learn whatever they want to with no constraints. Besides, this dimension includes group autonomy which means view of awareness of teachers as authority and other kinds of authorities such as parents or government policy. Individual autonomy is the last sub-dimension which signifies one's view of taking control of, and one's ability to make decisions about, the content, goals and purposes in learning English.

The fourth is sociocultural autonomy. The first sub-dimension is social-interactive which refers to one's views of learning with or from teachers and/or other learners, and social interaction is vital to develop learner autonomy. The cultural subdimension is the views of learning in different cultures.

For Oxford (2003), research should combine as many perspectives as possible and employ multiple methodologies in a study to better understand learner autonomy. For this reason, this study assessed learner autonomy in all four dimensions employing a mixed-methods design.

\section{Characteristics of autonomous learners}

Oxford (2015) explores psychological and sociocultural perspectives on autonomous learners. The psychological perspective describes autonomous learners as self-regulated, emotionally intelligent, resilient, psychologically engaged with meaningful tasks or materials, self-determined who have intrinsic motivation in learning, existentially free who can cope well with adversity and find solutions, and effective who can manage emotions and use a range of strategies relevant to their needs.

The sociocultural perspective introduces six more characteristics of autonomous learners. They include the mediated learner who develops selfregulation through assistance of more capable others. Second, the cognitively apprenticed learner is assisted by a more capable person in a community of practice. "A cognitive apprenticeship helps students to acquire, develop, and use learning strategies in authentic activities via interaction, social construction of knowledge, scaffolding, modelling, goal setting, peer sharing, and learner reflection" (Oxford, 2015, p. 64). Third, the socioculturally strategic learner uses and manages strategies. Fourth, the invested learner believes that he or she will gain something through language learning. Investment in learning will bring about effort which will result in resources that will enhance cultural capital, identity, and future desires. Fifth, the socio-politically free learner actively exercises freedom and uses it responsibly as well as engages in meaningful interactions with teachers and peers as a buddy critical thinker. Sixth, the selfefficacious learner is confident in his or her ability to successfully complete a task or achieve a goal. Based on social relationship, self-efficacy develops through reflecting on past experiences of success or failure, observing other people, and recognizes 'social persuasion' such as encouragement or discouragement from others.

\section{METHOD \\ Context of the study}

The students were in their first semester of MA ELT which is an international program in an international university in Thailand. Typically, the first-year courses include: Language teaching methodology, Research methodology, Foundation to language study, and Language testing and evaluation. The 
first researcher/author taught one of the courses, so she knew the student participants well and had positive relationship with all of them.

The program applies student-centered learning approach with an emphasis on inquiry-based learning, collaborative learning, task-based learning, and project-based learning. Students are required to give oral presentations, and complete term projects and term papers. Alternative assessment is mainly employed by every course. Final examination is administered in a few courses with a small proportion of the evaluation score. Although there is no course on learner autonomy, it is a mission of the program to train them to be autonomous through learning task performance and application of alternative assessment consisting of both formative and summative assessment. Instructors in the program are both native and non-native English speakers.

\section{Participants}

Altogether there were 19 first-year students in the program: 15 Chinese, 3 Burmese and 1 Thai. Among them, 5 are male and 14 are female with ages range from 21 to 40 . Only one male Chinese student had a 7-year full-time teaching experience at a high school while two were teacher assistants at schools in Myanmar. Other participants graduated with a bachelor's degree in different fields from their home countries and did not have prior teaching experiences.

\section{Research Design}

This study employed an explanatory mixed-methods design (Figure 1) which combines quantitative and qualitative methods within a single research project. A quantitative method (QUAN) using the online questionnaire was first carried out followed by quantitative data analysis. As for the limited participant size, only descriptive statistics were drawn quantitatively.

Subsequently, a qualitative method (Qual) which is a follow-up semi-structured interview was executed to explore what contributed to such level of autonomy and to triangulate so that the validity and reliability of the quantitative findings was established. The quantitative and qualitative data were analyzed separately. The qualitative results were used to expand on the findings of the quantitative study (Fraenkel et al., 2016).

\section{Figure 1}

The Explanatory Mixed-Methods Design

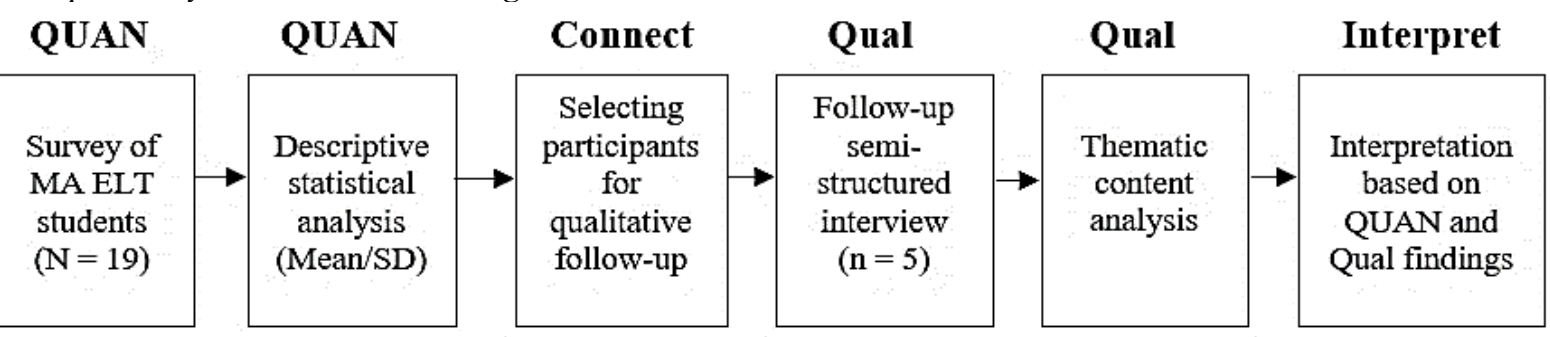

\section{Research instruments \\ Learner autonomy questionnaire}

The questionnaire adopted and adapted from the Measuring Instrument for Language Learner Autonomy (MILLA), originally developed by Murase (2015), was employed to collect quantitative data. The MILLA questionnaire was reported its reliability by the confirmatory factor analysis and the Cronbach's alpha of 0.94. The five-point Likert Scale questionnaire consists of 49 items in total: Technical dimension (11 items, e.g. "I make longterm plans for my study. ”), Psychological dimension (14 items, e.g. "I want to get a job where I use English in the future."), Political-Philosophical dimension (11 items, e.g. "The teacher and students should negotiate on the plans for studying."), Sociocultural dimension (13 items, e.g. "I sometimes adopt what other students are doing into my own learning."). The participants stated whether they strongly agreed, agreed, were uncertain, disagreed, or strongly disagreed with each statement. Their agreement of learner autonomy

reflected their level of autonomy. The rating scores of 4.21-5.00 means a level of learner autonomy is very high, 3.41-4.20 means high, 2.61-3.40 means moderate, 1.81-2.60 means low, and 1.00-1.80 means very low. The range of 0.8 for each level is typically calculated by the maximum value of the Likert-scale (5) minuses the minimum of the scale (1) and divided by the maximum value of the scale (5).

\section{Semi-structured interview}

Five participants: two high, one moderate and two low level of autonomy were purposively selected for the follow-up semi-structured interview after the analysis of the questionnaire findings. Their pseudo names are Sandra, Jenny and Mac from China, Mary and Kate from Myanmar. Based on the highest or lowest rated statements of each dimension, these follow-up questions were designed to elicit answers by asking them to provide explanations. 
1) What is your long-term goal that you set? How does the goal help your learning? (Technical Dimension)

2) How does motivation help you learn in this ELT program? (Psychological Dimension)

3) The questionnaire findings showed that students concerned more about teacher authority than parents or society. Why is that so? (Political-Philosophical Dimension)

4) The findings also suggested that students view teacher-student negotiation on the learning process is necessary. What do you think about the roles of teachers? (Political-Philosophical Dimension)

5) The findings showed a degree of teacherdependence but not that high. Can you explain? (Sociocultural Dimension)

\section{Data collection procedures}

Upon their approval to participate in the research project by signing the consent form, the participants completed the online questionnaire in class in early September 2019. Three months later after the analysis of the questionnaire findings, the follow-up interviews were conducted with each selected participant outside class time. The first researcher's good relationship with the participants, as stated earlier, should assure the validity of the findings of this study although this relationship and other contextual factors may impact all interview data (Benson, 2010). The researcher took notes of each interview which lasted for 20-30 minutes.

\section{Data analysis}

The scores of the questionnaire were computed for mean score and standard deviation (SD). Qualitative data analysis involved repeated reading of the responses (Benson, 2010) to generate themes as per each autonomy dimension. Upon discussion, agreement between the two researchers was reached regarding the emerging themes. Excerpts related to each generating theme are presented.

\section{RESULTS}

The questionnaire findings showed that, on average, the level of autonomy of all four dimensions was at a high level $($ Mean $=3.62, \mathrm{SD}=0.30)$. Each dimension was also at a high level as displayed in Table 1. This means that, on average, the participants were highly autonomous in every dimension of learner autonomy.

Table 1

Levels of Learner Autonomy

\begin{tabular}{lcccccc}
\hline \multicolumn{1}{l}{ Dimension } & N & Minimum & Maximum & Mean & SD & Level \\
\hline All Dimensions & $\mathbf{1 9}$ & $\mathbf{2 . 8 3}$ & $\mathbf{3 . 9 8}$ & $\mathbf{3 . 6 2}$ & $\mathbf{0 . 3 0}$ & High \\
Technical & 19 & 2.82 & 4.64 & 3.68 & 0.46 & High \\
Psychological & 19 & 3.00 & 4.78 & 3.92 & 0.40 & High \\
Political-philosophical & 19 & 2.64 & 4.27 & 3.55 & 0.53 & High \\
Socio- cultural & 19 & 2.77 & 3.69 & 3.31 & 0.27 & High \\
\hline
\end{tabular}

The content analysis of the interview findings illustrates four emerging themes in relation to each autonomy dimension as follows:

Theme 1. Technical Dimension: Use of Metacognitive Strategies Through Professional Goal Setting

Technical dimension is the ability to use cognitive and metacognitive strategies. The quantitative findings suggested that goal setting was rated the highest and prominently contributed to a high level of technical autonomy. All of the participants stated their long-term goal which is to become a teacher in a future. Goal setting is one of the metacognitive strategies that is important to be successful in learning. Mac said that:

"My goal is to be more professional and qualified in terms of English language learning and teaching. It's my motivation to gain more academic knowledge. I'll put what I learn into my future teaching job. "
Sandra set a longer-term goal which showed her future plan after graduation and clearly stated the reasons why she set such goal which seemed to act like a learning condition and drove her for a sustainable learning effort.

"To have a doctoral degree in order to teach in a college. ... My goal pushes me to do something. I came here to study, not consider other things. Especially during semester 1, I needed to adapt myself. Until now, I still need to work hard. This is the only goal that I came here."

Similarly, Mary, who had clear goals which related to teaching professional and life stated that:

"I have two goals. First is to help students in my convent and second is to develop my religious life which will make me holy (as a nun). ... I can learn and know by myself. Compared with my past learning, it's not that good as teachers were not qualified." 
The focal point that emerges from the comments is the significance of setting a long-term goal related to future career and way of life which acts as a strong drive or motivation for learning to achieve such goal.

\section{Theme 2. Psychological Dimension: Intrinsic and Extrinsic Motivation in Support of Autonomous Learning}

Psychological autonomy deals with intrinsic and extrinsic motivation and affective sub-dimensions. Motivation greatly contributed to the high psychological autonomy of the participants. Supported by the questionnaire findings showing the like of English learning, the Chinese students expressed their motivation to learn which integrates both intrinsic and extrinsic motivation. They mentioned learning enjoyment and their wish to get a good teaching job or getting good grades which drove their learning. Sandra said that:

"I'm motivated because I want to be a teacher in a future. I enjoy learning. I want to improve my English proficiency, especially writing. I've learned English for many years. I'll be proud and more confident.... It's interesting to know the whole process. I work hard. I enjoy to do everything here."

Mutual beneficial relationship of extrinsic and intrinsic motivation was expressed by Jenny reflecting the importance of grades that motivated her for her study perseverance.

"I can't bear low grades. It's a failure if I get bad grades. This helps me to work as hard as possible. If I get low grades, it means I don't work hard enough."

Mary showed her intrinsic motivation to learn because of content matters and teaching methodologies she experienced from the program:

"In ELT program many methodologies and subjects are useful. I know methods and techniques and I'll use them to help my students."

The main point emerging from the findings is that both intrinsic and extrinsic motivation which closely relates to professional goal setting is very powerful to sustain their learning effort. This increases their interest in learning which will be advantageous for their teaching job in the future.

\section{Theme 3. Political-philosophical Dimension: Teacher as authority partner in a negotiable learning process}

This dimension concerns freedom to learn, group autonomy viewing teacher as authority, and individual autonomy signifying one's ability to take control of own learning. The questionnaire findings showed a higher concern about teacher authority than parents or society. They were then asked about the roles of teachers. Mac strongly supported the findings on teacher authority saying that:

"Actually, I totally believe in the findings. In my opinion, I concentrate on teacher authority in terms of teaching, receiving knowledge from teachers. Teachers are main sources of knowledge. ... Teachers give a right direction to us to achieve our goals. "

When asked about his thought on the results showing a necessity for teacher-student negotiation on the learning process, Mac expressed a mutual relationship between teachers and students.

"Before I came here, I relied on my teachers as they're qualified. But my concept is totally changed. I think teachers have something they don't know, and students know something. We can share knowledge and negotiate. "

Sandra held similar attitudes toward teacher authority and learning negotiation between teachers and students. She said that:

"I agree, especially in my country. Students, especially young children want to follow their teachers. Teacher's authority is important. But for college students, not too much. They have critical thinking. And compared with parents for academic, teachers' suggestions about subject matters, teachers are still important. Teacher authority is important. Student-teacher negotiation is very important and necessary as student needs teacher's suggestions. Teacher should be a facilitator helping and suggesting and engaging students to learn."

Mary also suggested the similar conceptions on teacher authority and learning negotiation. She added that:

"In the past I thought learning development depended on teachers, but now I changed my mind. Even teachers focus on teaching; students don't learn if students don't prepare to learn. Parents are important to prepare their children. Parents should support teachers. Society too, especially for young learners. For adult learners, they don't depend on teachers. We can manage or think, responsible for our learning, not depending on teachers and parents."

The important role of teacher as a partner in a negotiable learning process emerged. Teachers still have authority to provide guidance and support in terms of both cognitive and affective aspects and this therefore highlights the crucial dimension of autonomy on teacher-student negotiation. 
Theme 4. Sociocultural Dimension: Preference for self-dependence and collaborative learning This dimension includes social-interactive and cultural sub-dimensions which deal with views of learning with or from others and in different cultures respectively. All of them held similar views on a degree of teacher dependence. They accepted that to a certain extent they needed to depend on teachers but in a sense that they only needed guidance on resources and textbooks in order to learn by themselves as the ELT contents are brand new to them. The interview showed that they preferred to rely on themselves as Sandra commented.

"I think if I get some ideas, I'll be clear about my weakness. Teachers will encourage me to be confident to go on my learning. I just want guidance, not everything from my teachers. I don't want to rely on a teacher. But you want encouragement from teachers like Well done! You did a good job! As you learn by yourself all the time, if teachers give some encouragement, I'm more confident as everyday I'm doing the right thing."

Similarly, Jenny viewed that:

"That doesn't mean we have to depend on teachers all the time. Some students can get inspiration from the teachers."

Kate expressed her preference for self-study and collaborative learning which reflects less dependence on teachers and values social interaction among peers.

"Once I learn on my own, I feel satisfied. I prefer to work in group because we can share our opinions from different perspectives. ... I learn something from group discussion. Yes, I like to learn something no matter from whom" (when asked: Are you happy with your learning?)

The findings on a low to moderate degree of teacher dependence required for their learning reveals a preference for self-dependence and collaborative learning. Once they received guidance from teachers, they are able to take charge of their own learning with more confidence.

\section{DISCUSSION}

The findings were discussed in response to each autonomy dimension with an attempt to provide theoretical and instructional implications.

\section{The power of long-term professional goal and a growth mindset}

For the technical dimension, goal setting and creating conditions to learn best contributed the most to the high degree of learner autonomy. The findings from the interview distinctly highlighted the significance of setting a long-term goal related to a future career or way of life. As shown by the findings, the long-term goal of becoming a professional and qualified English teacher is challenging especially for Chinese students. The participants are aware that they need ELT knowledge and skills as well as English proficiency. With the goal, they know how to create a learning condition to achieve such goal. Thus, goal setting appears to automatically help creating motivation to construct learning conditions.

The results show that long-term professionrelated goal setting is powerful to develop a growth mindset of the learners to become self-regulated and autonomous learners. It can turn learners to be the invested and determined learners who put sustainable effort to work hard to accomplish such goal. According to Ryan and Mercer (2011), a growth mindset facilitates optimistic academic growth which "enables learners to become more motivated, autonomous and self-regulated by setting more challenging goals, making them more willing to take risks, persist and adapt in the face of difficulties, and approach work or study in a purposeful strategic manner" (p.163-164).

The findings of this study clearly reveal a positive relationship between a long-term professional goal and a growth mindset development. However, such future goal must be achievable and realistic which can be viewed as worthwhile putting effort and perseverance. Learning determination can result in a development of learner autonomy in a sense of holding a belief in one's own ability and effort or action worthy of goal attainment as nothing is impossible for the growth mindset.

The power of long-term goal relevant to a future career on a creation of a growth mindset calls for teaching students of all ages to set a feasible and doable goal. For young learners, setting a shortterm learning goal is recommended while mature students should be trained to set a long-term goal preferably related to their future professions.

\section{Ideal $\mathrm{L} 2$ self and visions for the future}

Among the four dimensions of learner autonomy, psychological dimension, which mainly deals with learning motivation, showed the highest score especially the like of English language and English learning. The interview findings supported that the participants have both intrinsic and extrinsic motivation to learn autonomously and their motivation closely related to their professional goal, that is, to be a teacher of English.

This thus generated the second theme: Intrinsic and extrinsic motivation in support of autonomous learning. The findings are in line with the work of Swatevacharkul and Boonma (2020) revealing that learner autonomy is in fact motivation to learn. According to Oxford (2015), one characteristic of 
autonomous learners in relation to the psychological perspective is having intrinsic motivation in learning. However, this study also confirms the equivalent importance of extrinsic motivation to help learning if extrinsic motivation strongly supports intrinsic motivation. In this case, the participants' extrinsic motivation related to getting a good job or to become a teacher drives for intrinsic motivation to work hard. At the same time, they enjoyed their learning to gain the utmost knowledge and skills to equip themselves as qualified teachers of English. Therefore, the findings suggest that both intrinsic and extrinsic motivation is equally crucial for learning.

The possible explanation for the participants' high learning motivation can be Ideal L2 Self and their visions for the future. For Dörnyei and Ryan (2015), the Ideal L2 Self based on the L2 motivational self-system is "a representation of attributes that someone would ideally like to possess (i.e. representation of hope, aspiration, or wishes)" (p. 87). The Ideal Self is a powerful motivator for L2 learning as learners desire to reduce the discrepancy between their actual and ideal selves. "If people see a discrepancy between this and their current stage, they may be motivated to learn a new language or further develop their proficiency in an existing one" (Dörnyei \& Ryan, 2015, p. 87). In this case, the participants clearly demonstrated that they wish to become a qualified teacher of English in the future. They also thrive to improve their English proficiency as it is important for the ELT teachers. These are the reasons why they are willing to work hard.

Clearly, the Ideal L2 Self is motivated by the visions for the future which creates strong willpower and self-determination for learning effort and sustainability. It also assists development of goaloriented behaviors. At this point, it seems possible to say that there are relationships among professional goal setting, a growth mindset, and the Ideal L2 Self which is closely related to vision (Dörnyei, 2005). Thus, "where there is a vision, there is a way" (Dörnyei \& Kubanyioba, 2014, p. 2).

In other words, the Ideal L2 Self, motivated by visions for the future, positively associates with learner autonomy. The pedagogical implication lies on helping students particularly at basic or tertiary educational levels to have their Ideal L2 Selfmotivation and create a vision for their future which goes beyond a language classroom. As with the cases of the postgraduate students in the ELT program, they can see clearly what and why they wish to become after graduation.

\section{Preferences for positive freedom and group autonomy}

In relation to the political-philosophical autonomy which includes positive and negative freedom, and group and individual autonomy, the striking quantitative results were on a teacher-student negotiation on the goals in students' learning and freedom to decide on such goals and learning plans.

This reflects the important role of teacher as a partner in a negotiable learning process and thus generated the theme 3: Teacher as authority partner in a negotiable learning process. The qualitative data provided the insights that teachers, compared to parents or society at a larger level, have more authority in a sense of providing learning guidance and support in terms of both cognitive and affective aspects. The findings support Benson's (2010) argument that "from the students' perspective, ... teachers are the most immediate representatives of educational authority" (p. 263). This reinforces the crucial roles of teachers in a process of autonomy development which is supported by the recent research revealing autonomy can be nurtured by teachers (Swatevacharkul \& Boonma, 2020) who must be professional with appropriate pedagogical practice (Ramadhiyah \& Lengkanawati, 2019).

The findings on the participants' concern about the teachers who are authority partners in a negotiable learning process may be explained by their preference for positive freedom and group autonomy which contribute to their high level of autonomy in this dimension. They sought some freedom to control their learning with agreement of the teachers as they are aware that they cannot have a full freedom for their learning. They still need to rely on the teachers' help and support on the course contents suggestions. However, they do not wish to fully rely on the teachers. Instead, they aspire to be an agent of their own learning but with direction, help and support from teachers.

The results also suggested that teachers are viewed as essential authorities in taking on the roles of resource and facilitator. Teachers are crucial to transform the learners to be a change agent in their learning process. As Mary expressed, her conception of learning was changed from full teacher-dependence to self-dependence because the teachers in the ELT program are qualified to provide good learning experiences to her which is not the same case of her past teachers in her home country. In line with the research work in Indonesia, to change the students' perspectives and strategies, professional teacher development is essential (Ramadhiyah \& Lengkanawati, 2019).

Theoretically, reactive autonomy is preferable for the ELT graduate students. Teachers assist in establishing a learning direction which will enable learners to further organize resources autonomously by themselves (Littlewood, 1999). Clearly the findings reveal that in the Southeast Asian learning culture and context, full autonomy may not be appropriate. As suggested by Brockett and Hiemstar (1993), the autonomy expectation of the learners must be balanced with the conditions of learning situations. Otherwise, learner autonomy 
development is not fully effective and learning outcomes may not be favorable.

The first teaching implication lies on professional qualities of the teachers in terms of both subject knowledge and teaching methods. The second one is related to an awareness of the teachers to provide and allow students to exercise their authority to become more autonomous, based on appropriate degree of teacher's help. Providing them with opportunities to decide on some classroom tasks or project work is helpful. Allowing them to choose their own topic for a term paper or project is a simple but effective way to increase their autonomy. Group discussion is also beneficial to empower them to take part in a learning negotiation process with their peers which can promote decision making, knowledge sharing and critical thinking skills. All of these are the characteristics of autonomous learners.

\section{Collaborative learning and learner autonomy development}

In relation to the sociocultural dimension, $a$ preference for self-dependence and collaborative learning theme emerged and the quantitative finding evidently showed that the item on "Students can help each other learn" was rated the highest of all the questionnaire items (Mean $=4.53, \mathrm{SD}=0.70$ ). This obviously displays the participants' view on the value of social interaction among peers in promoting learner autonomy through collaborative learning which constructs a capacity of self-dependence. Supported by the interview findings, the participants depend less on their teachers. Rather, they preferred self-reliance.

Within a sociocultural theory, learning is a social, dynamic and collaborative process (Mann \& Walsh, 2017). Collaborative learning provides chances for peer interaction and interdependence which leads to learning acquisition. The social relationship between peers is thus vital in constructing learner autonomy. The findings assert Murray's (2014) argument that autonomy is developed through interdependence and collaboration in a social setting of a language classroom. As evidence shows, students enjoy collaborative learning because they can learn from their peers and it does help them become more autonomous.

The nature of graduate study particularly in the ELT program which emphasizes self-directed learning and collaborative learning through class discussion, group activities and group project work may form their belief in social interaction. Thus, their learning behavior is shaped by becoming mediated learners who construct self-regulation in learning through help of more capable people, in this case, their peers or even a teacher. Within a zone of proximal development or ZPD (Vygotsky,
1986 cited in Murphy, 2014), learner autonomy emerges.

Autonomous learning is therefore a social learning process which encourages learners to be more willing to learn independently or with less teacher-dependence. Theoretically, social interaction is effective to nurture learner autonomy and interactional competence is essential for autonomous learners. Pedagogical implication lies on an emphasis on social interaction as promoted though collaborative and scaffolding learning which is considered as a condition for learner autonomy cultivation.

\section{CONCLUSION}

The findings illustrated that, on average, the ELT student participants of this study are highly autonomous in all four dimensions of learner autonomy.

The technical dimension was found to be high mainly due to a use of metacognitive strategies through goal setting. Specifically, a long-term goal related to their future profession was found to be powerful in creating a growth mindset. Such mindset contributes to sustainable effort and perseverance to achieve that goal, in turn, resulting in a development of learner autonomy.

Under the psychological dimension, it was revealed that intrinsic and extrinsic motivation is in support of autonomous learning. The study's participants are highly motivated for autonomous learning because of their Ideal L2 Self and their visions for the future. They wish to become a qualified teacher of English which drives them to maintain their learning motivation.

To develop political-philosophical autonomy, teachers are a major contributive factor to promote learner autonomy. They can empower students to have chances for learning negotiations.

The high degree of sociocultural autonomy can be explained as a preference for self-dependence and collaborative learning. Indeed, perceived value of social interaction among learners through collaborative learning and reduced degree of teacher dependence helps cultivate the development of learner autonomy.

For further research, it is recommended that more participants in other ELT programs be included for a larger scale data collection which will ensure more reliable findings and increase generalizability of the research findings. A longitudinal study on the same group of participants is also suggested to compare their level of autonomy between the first day they enter into the program and the last day of their study so as to explore whether there will be a difference of their autonomy level and what factors contribute to such difference if any or no difference. For teaching and learning, a course on learner autonomy should be offered so 
that the ELT students are well trained and equipped with knowledge of autonomy and how to implement it effectively.

\section{REFERENCES}

Arshiyan, P., \& Pishkar, K. (2015). A study of Iranian professors' perceptions of EFL university students' autonomy. Journal of Applied Linguistics and Language Research, 2(5), 197-214.

Benson, P. (1997). The philosophy and politics of learner autonomy. In P. Benson \& P. Voller (Eds.), Autonomy and independence in language learning (pp. 18-34). Longman.

Benson, P. (2010). Teacher education and teacher autonomy: Creating spaces for experimentation in secondary school English language teaching. Language Teaching Research, 14(3), 259-275. https://doi.org/10.1177/1362168810365236

Benson, P. (2011). Teaching and researching autonomy. Pearson.

Benson, P. (2015). Forward. In C. J. Everhard \& L. Murphy (Eds.), Assessment and autonomy in language learning (pp. 8-11). Palgrave Macmillan.

Brockett, R., \& Hiemstar, R. (1993). Self-direction in adult learning: Perspectives on theory, research, and practice. Routledge.

Derakhshan, A., \& Taghizadeh, M. (2020). Investigating the role of English language teachers' professional identity and autonomy in their success. Issues in Language Teaching, 9(1), 1-28. https://doi.org/10.22054/ilt.2020.52263.496

Dickinson, L. (1987). Self-instruction in language learning. Cambridge University Press.

Dickinson, L. (1995). Autonomy and motivation a literature review. System, 23(2), 165-174. https://doi.org/10.1016/0346-251X(95)00005-5

Dörnyei, Z. (2005). The psychology of the language learner: Individual differences in second language acquisition. Lawrence Erlbaum Associates.

Dörnyei, Z., \& Kubanyiova, M. (2014). Motivating learners, motivating teachers: Building vision in the language classroom. Cambridge University Press.

Dörnyei, Z., \& Ryan, S. (2015). The psychology of the language learner revisited. Routledge.

Everhard, C. J. (2015). The assessment-autonomy relationship. In C. Everhard \& L. Murphy (Eds.), Assessment and autonomy in language learning (pp. 8-34). Palgrave Macmillan.

Fraenkel, J. R., Wallen, N. E., \& Hyun, H. H. (2016). How to design and evaluate research in education. ( $9^{\text {th }}$ edition). McGraw-Hill.

Holec, H. (1981). Autonomy in foreign language learning. Pergamon.
Little, D. (1995). Learning as dialogue: The dependence of learner autonomy on teacher autonomy. System, 23(2), 175-181. https://doi.org/10.1016/0346-251X(95)00006-6

Littlewood, W. (1999). Defining and developing autonomy in East Asian contexts. Applied Linguistics, 20(1), 71-94. https://doi.org/10.1093/applin/20.1.71

Mann, S., \& Walsh, S. (2017). Reflective practice in English language teaching: Research-based principles and practices. Routledge.

Murase, F. (2015). Measuring language learner autonomy: problems and possibilities. In C. J. Everhard \& L. Murphy (Eds.), Assessment and autonomy in language learning (pp. 35-63). Palgrave Macmillan.

Murphy, L. (2014). Autonomy, social interaction, and community. In G. Murray (Ed.), Social dimensions of autonomy in language learning: A distant language learning perspective (pp. 119-134). Palgrave Macmillan.

Murray, G. (2014). Exploring the social dimensions of autonomy in language learning. In G. Murray (Ed.), Social dimensions of autonomy in language learning: A distant language learning perspective (pp. 3-11). Palgrave Macmillan.

Oxford, R. (2003). Toward a more systematic model of L2 learner autonomy. In D. Palfreyman \& R. C. Smith (Eds.), Learner autonomy across cultures: Language education perspectives (pp. 75-91). Palgrave Macmillan.

Oxford, R. (2015). Expanded perspectives on autonomous learners. Innovation in Language Learning and Teaching, 9(1), 58-71. https://doi.org/10.1080/17501229.2014.995765

Ozturk, G. (2019). Fostering learner autonomy among pre-service EFL teachers: A mixedmethod study. International Journal of Educational Psychology, 8(3), 298-316. http://dx.doi.org/10.17583/ijep.2019.4427

Palfreyman, D. (2003). Introduction: Culture and learner autonomy. In D. Palfreyman \& R. C. Smith (Eds.), Learner Autonomy across Cultures: Language Education Perspectives (pp. 1- 19). Palgrave Macmillan.

Ramadhiyah, S., \& Lengkanawati, N. S. (2019). Exploring EFL learner autonomy in the 2013 curriculum implementation. Indonesian Journal of Applied Linguistics, 9(1), 231-240. https://doi.org/10.17509/ijal.v9i1.15626

Ryan, S., \& Mercer, S. (2011). Natural talent, natural acquisition and abroad: Learner attributions of agency in language learning. In G. Murray, X. Murray, \& T. Lamb (Eds.), Identity, motivation and autonomy in language learning (pp. 160-176). Multilingual Matters.

Smith, R. (2000). Starting with ourselves: Teacherlearner autonomy in language learning. In B. Sinclair, I. McGrath, \& T. Lamb (Eds.), 
Learner autonomy, teacher autonomy: Future directions (pp. 89-138). Longman.

Swatevacharkul, R., \& Boonma, N. (2020). Learner autonomy: Attitudes of graduate students in English language teaching program in Thailand. LEARN Journal, 13(2), 176-193.
Tassinari, M. G. (2015). Assessing learner autonomy: A dynamic model. In C. J. Everhard \& L. Murphy (Eds.), Assessment and autonomy in language learning (pp. 64-88). Palgrave Macmillan. 